\title{
Discussão conceitual entre o processo de obsolescência espacial urbana e o preço da terra e do ambiente construído
}

Le processus d'obsolescence spatiale urbaine et les prix de la terre et du milieu construit : un débat conceptuel

Conceptual discussion between the urban spatial obsolescence process and land price and the built environment

Discusión conceptual del precio del suelo, el ambiente construido y el proceso de obsolescencia espacial urbana

\section{André Vinícius Martinez Gonçalves}

\section{(2) OpenEdition}

\section{Journals}

\section{Edição electrónica}

URL: https://journals.openedition.org/espacoeconomia/19448

DOI: 10.4000/espacoeconomia. 19448

ISSN: 2317-7837

\section{Editora}

Núcleo de Pesquisa Espaço \& Economia

\section{Refêrencia eletrónica}

André Vinícius Martinez Gonçalves, «Discussão conceitual entre o processo de obsolescência espacial urbana e o preço da terra e do ambiente construído ", Espaço e Economia [Online], 21 | 2021, posto online no dia 12 julho 2021, consultado o 22 julho 2021. URL: http://journals.openedition.org/ espacoeconomia/19448; DOI: https://doi.org/10.4000/espacoeconomia.19448

Este documento foi criado de forma automática no dia 22 julho 2021.

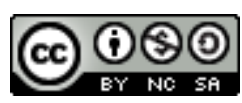

Espaço e Economia - Revista brasileira de geografia econômica est mise à disposition selon les termes de la licence Creative Commons Attribution - Pas d'Utilisation Commerciale - Partage dans les Mêmes Conditions 4.0 International. 


\title{
Discussão conceitual entre o processo de obsolescência espacial urbana e o preço da terra e do ambiente construído
}

\author{
Le processus d'obsolescence spatiale urbaine et les prix de la terre et du milieu \\ construit : un débat conceptuel
}

Conceptual discussion between the urban spatial obsolescence process and land price and the built environment

Discusión conceptual del precio del suelo, el ambiente construido y el proceso de obsolescencia espacial urbana

André Vinícius Martinez Gonçalves

\section{Introdução}

1 David Harvey (2013) assinala que o capitalismo é extremamente dinâmico e inevitavelmente expansionista. Impulsionado pelo motor da acumulação e abastecido pela exploração da força de trabalho, constrói uma força que revoluciona permanentemente e reformula o mundo em que vivemos. O que nos interessa da assertiva de Harvey é trazer o debate para uma escala de mundo específica, no caso, a cidade e uma de suas especificidades: o processo da obsolescência espacial urbana.

2 A reprodução do sistema tem em seus mais diversos agentes econômicos o objetivo de, por via da acumulação de capitais e da exploração da força de trabalho, obter diferentes modalidades ou formas combinadas de remuneração - no caso o lucro, os juros e a renda. Para alcançar tais condições, o Capital, entre outras ações, apropria-se e organiza múltiplos territórios sob uma lógica de produção espacial marcada por diferentes combinações, articulações e densidades em distintos lugares, escalas e tempos. 
3 Em dois artigos sobre a obsolescência espacial urbana (GONÇALVES, 2018 e 2020), assinalamos a imprecisão e superficialidade geográfica do conceito de deterioração urbana. Em contraposição, trabalhamos com a ideia de que a problemática da obsolescência expressa a lógica e atuação dos agentes do mercado fundiário encarregados da produção espacial da cidade, que a moldam em diferentes tempos e territórios, com ambientes construídos marcados por distintas formas, funções, conteúdos técnicos e sociais, bem como diferentes modos de circulação de capitais.

4 O termo deterioração urbana, dada a sua carga ideológica, quando considerado para uma análise geográfica do espaço urbano impede uma análise que ultrapasse a aparência da paisagem - erro comum em muitos estudos urbanos e geográficos sobre a cidade. A leitura da paisagem é ponto de partida ${ }^{1}$, mas não explica os processos.

5 A ideologia da deterioração oculta o discurso higienista e, quando lançada sobre os ambientes construídos, é argumento para justificar as intervenções por parte do Estado e do setor imobiliário no sentido da produção de novos territórios na cidade. As operações urbanas consorciadas vigentes na cidade de São Paulo são exemplo concreto dessa realidade ${ }^{2}$.

6 Aqui não se nega a necessidade de modernização dos ambientes que possuem problemas de ordem física, funcional e econômica; porém na lógica da deterioração o que impera é a demolição em nome do processo da revalorização desses territórios.

7 Exemplos não faltam de territórios, marcados por ambientes construídos ditos deteriorados que são colocados a baixo para dar lugar a empreendimentos residenciais de alto padrão ou edifícios de escritórios coorporativos, como o caso citado por Ramos (2006), "das atuais nas imediações do eixo viário composto pelas vias Francisco Matarazzo/Carlos Vicari e Ermano Marchetti/Marquês de São Vicente, envolvendo parte da Barra Funda e da Água Branca e Mooca ${ }^{3}$ ", que em tempos pretéritos foram áreas e bairros industriais da cidade de São Paulo.

8 O discurso da revitalização - no sentido de ocultar que as operações urbanas resultam sobretudo em ganhos financeiros expressivos para os agentes econômicos envolvidos, em especial, àqueles ligados ao setor imobiliário - tem como objetivo trazer para o território dito degradado uma falsa nostalgia de um passado onde tudo na cidade era melhor, seja lá o que isso queira dizer.

9 A consequência imediata dessas ações é a expulsão da população pobre para as periferias. A revalorização da terra-mercadoria impede que essa classe tenha acesso ao novo ambiente construído. Essa parte da classe trabalhadora, somada aos moradores em situação de rua, são colocados como os responsáveis pela deterioração do território nos discursos diretos e indiretos promovidos pelo setor imobiliário, pelo Estado e pela mídia.

10 Outra realidade quando se trata do discurso da deterioração urbana em São Paulo diz respeito às edificações e ambientes construídos que se encontram em estado de abandono, ociosidade e subutilizados e que não cumprem a função social da propriedade $^{4}$. A partir da legislação vigente ${ }^{5}$, até 2018, 1.385 imóveis na cidade haviam sido notificados pela prefeitura, a maioria localizados na região central tradicional e $\operatorname{adjacências}^{6}$ (figura 1 ). 
Figura 01: Imóveis ociosos e subutilizados São Paulo - Região Central e entorno (2018)

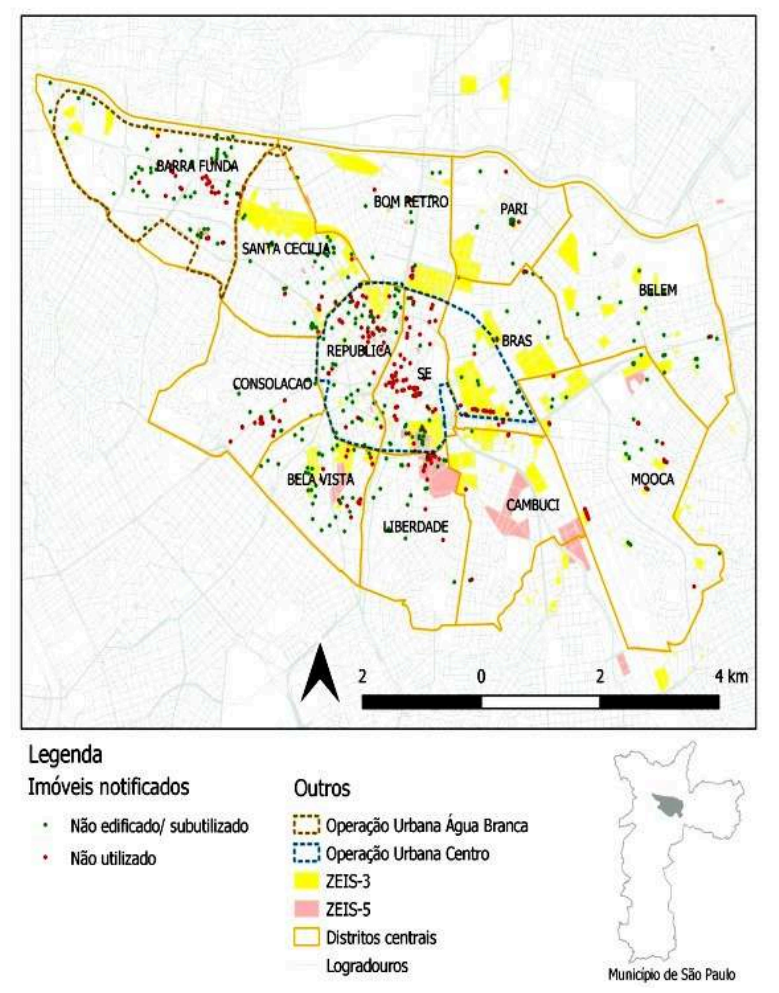

Base cartográfica: MDC (2004). Fonte: CEPEUC/PMSP, 2018.

11 Seria possível recuperar, modernizar e destinar parte considerável dos imóveis obsoletos da região central de São Paulo para atenuar a problemática do déficit habitacional ${ }^{7}$, sobretudo, por moradia popular em São Paulo8? A resposta obviamente é sim. Para fins didáticos, supondo 1.000 prédios com média de 10 andares e capacidade de abrigar 4 unidades (apartamentos) por andar, teríamos 40.000 unidades.

Vozes contrárias, em especial economistas e urbanistas que não colocam em suas contas as reais demandas da população pobre, defendem que é mais barato construir novas edificações do que recuperar as velhas e/ou modernizar as antigas. Justificam ainda que diante da atual legislação, as edificações obsoletas não conseguiriam atender as exigências de segurança, mobilidade interna, infraestrutura entre outros. Um discurso absolutamente falso. Legislações possuem o aspecto técnico, mas acima de tudo têm uma dimensão política.

A deterioração possui um caráter higienista, uma vez que atende aos interesses do setor imobiliário e imputa aos pobres a pecha de agentes da degradação. Adotar o conceito de obsolescência permite jogar luz sobre o modo como os proprietários desses imóveis operam, norteados pela lógica da especulação imobiliária. Edificações abandonadas, impostos atrasados, porém "ativos" em mãos - ou seja, a terra e localização no qual está situado o imóvel abandonado podem propiciar aos proprietários dos imóveis ganhos futuros.

Modernizar uma edificação, um prédio em situação de obsolescência na área central é mais barato, pois mesmo que o custo de modernização de um imóvel seja mais elevado que construir um novo nas franjas da cidade, há que se considerar que a região central já está dotada de toda uma ampla gama de infraestrutura, coisa que não ocorre na 
periferia. Construir edificações nas periferias exige levar para essas localidades saneamento básico, ruas, avenidas, transporte público, enfim, um volumoso conjunto de infraestrutura e equipamentos de uso público.

Adotar o processo da obsolescência espacial urbana como conceito corresponde a defender a necessidade de superação do termo deterioração urbana. A obsolescência espacial permite a compreensão, por exemplo, a partir das condições geográficas dos ambientes construídos, dos fatores pelos quais esses não conseguem atender de modo satisfatório as exigências de remunerações do capital, principalmente os setores econômicos ligados ao mercado imobiliário, bem como as demandas de retorno econômico para o Estado (Gonçalves, 2015). Essa última questão, como indicamos, é oculta para a população.

16 Como forma de elucidar uma fração dessa problemática urbana, os preços praticados pelo mercado imobiliário no ambiente construído da cidade evidenciam o processo espacial da obsolescência urbana. Ao considerar as reflexões iniciais aqui apresentadas, passamos a tratar de modo indissociável o preço da terra, o ambiente construído e a obsolescência espacial urbana.

\section{O Preço da Terra, o Ambiente Construído e a Obsolescência Espacial Urbana}

17 Todos os objetos ou coisas que nos cercam possuem um valor, seja porque eles nos representam algo, são úteis de alguma forma, agem com maior ou menor intensidade com nossas emoções, memórias ou sentidos, seja porque entendemos que um objeto é fruto de um trabalho realizado, no caso, produzidos pelos homens ou pela natureza.

mosso dia a dia utilizamos de maneira banalizada preço e valor de coisas e objetos como equivalentes: um objeto custa ou tem um preço de dez reais ou esse mesmo objeto possui um valor de dez reais.

19 Também no dia a dia atribuímos valores diferentes para coisas e objetos novos ou velhos e que possuem preços distintos entre si. É possível deter um objeto de preço elevado e lhe atribuir um valor sentimental ou de uso pequeno e também é possível deter um objeto de preço irrisório e lhe dar um valor sentimental elevado ou de uso intenso, porém, o nosso objetivo é discutir a categoria valor como relação social mercantilizada

Falar em obsolescência urbana na realidade capitalista é remeter a um múltiplo conjunto de ambientes construídos, mercadorias consumidas e usadas no decorrer do tempo. Para refletir sobre a relação entre preço e ambiente construído, é de fundamental importância tratar o sentido e significado da mercadoria em nossa realidade. Marx (2013, p. 97) ${ }^{9}$ nos lembra que "a riqueza das sociedades onde reina o modo de produção capitalista aparece como uma 'enorme coleção de mercadorias', e a mercadoria individual como sua forma elementar".

21 A magnitude dos valores corporificados nas mercadorias pelo sistema capitalista não reflete a sua origem e só pode ser refletida sob a condição do trabalho humano. Segundo Rosdolsky (2001), tempo de trabalho socialmente necessário corresponde a um imperativo social coletivo, produzindo um determinado valor de $u^{10} \mathrm{o}^{10}$ e ao mesmo tempo a magnitude de seu valor. 

também é por meio dele que a existência social se realiza e emancipa-nos da natureza. No campo da economia existem duas formas para se definir valor: 1) a teoria do valorutilidade, que parte da relação entre homem e natureza, onde a partir das suas demandas os homens, de acordo com suas subjetividades e satisfação de suas necessidades, produzem objetos atribuindo-lhes valor; e 2) a teoria do valor-trabalho, onde "o valor é fruto das relações que se criam entre homens na atividade econômica" (SINGER, 1987, p. 12).

No sistema capitalista, não basta produzir somente o valor de uso para saciar uma determinada necessidade individual. Na dimensão da produção de mercadoria, para que seja estabelecido um valor de uso social, deve-se produzir valores de usos para outros que serão cambiáveis no mercado.

No modo de produção capitalista, à medida em que uma fração da capacidade de trabalho dos homens é absorvida e transformada em força de trabalho, essa mercadoria será como qualquer outra mercadoria consumida. Se, anteriormente a essa realidade, $o$ trabalho estava vinculado à produção de valores de usos e esses eram reconhecidos pelos seus produtores; no sistema capitalista aquilo que o trabalhador realiza, a produção de valores de uso, é externo a ele, pois os resultados de suas atividades pertencem aos capitalistas.

trabalhador crer que há uma relação de igualdade contratual na relação com a firma, ele não escolhe o que e como produzir, ele não determina sua jornada de trabalho $\mathrm{e}$ muito menos o seu salário. Isso lhe é externo e imposto. Há, portanto, uma sujeição da força de trabalho que é transformada em mercadoria para o capitalista, que a converte na produção para render valores de uso para terceiros, com o objetivo de acumular para si valores de troca e ampliação do seu capital.

26 Cabe aqui um esclarecimento: vários manuais de economia e correntes marxistas reproduzem de modo simplista e naturalizado que a mercadoria possui um duplo valor: de uso e de troca. Quando surge nos primeiros parágrafos do Capital - Livro I que a mercadoria é valor de uso e valor de troca, ignora-se tratar de análise crítica de Marx aos antecessores no campo da Economia Política, em especial, Adam Smith e David Ricardo ${ }^{11}$.

27 A mercadoria como unidade isolada é valor de uso, mas não é valor de troca. Só será valor de troca quando o valor de uma determinada mercadoria for colocada no processo da troca. Valor de troca é a forma necessária de expressão de valor, em relação quantitativa, onde a proporção na qual valores de uso de uma espécie se trocam por valores de uso de outra espécie.

ndo uma mercadoria é produzida, o seu valor de uso demanda de uma inversão para ser consumida - isto é, o valor da mercadoria, inicialmente carregado pelo valor de uso, só se realiza na troca com outra mercadoria, em nossa sociedade, o dinheiro, visto que esse é a expressão geral do valor comum a todas as mercadorias.

29 Correntes que possuem em sua gênese a categoria "valor-utilidade ${ }^{12}$ " defendem que a utilidade da mercadoria é que define o seu preço em uma relação subjetiva entre os compradores e as mercadorias. Nesse sentido, as taxas de lucro auferidos pelas empresas também ficariam atreladas a esse subjetivismo, o que é absolutamente falso ${ }^{13}$. A teoria do valor trabalho considera que o valor é incorporado na mercadoria a partir

Espaço e Economia, 21 | 2021 
de um tempo médio necessário para a sua produção (tempo de trabalho social médio para a produção). Quando esta estiver pronta, será vendida tendo como parâmetro o tempo de trabalho cristalizado nela, que é o que definirá o preço no processo da troca que ocorre no mercado.

$\mathrm{Na}$ "enorme coleção de mercadorias" os valores não podem ser reduzidos ao mero tempo de trabalho socialmente necessário para produzi-las, pois reduziria o valor a somente uma dimensão quantitativa. $O$ valor na perspectiva marxista é uma qualidade social e só se realiza quando ocorre a troca entre mercadorias. Não pode ser percebido pelos nossos sentidos, não se pode tocar ou cheirar. $O$ valor é a maneira pela qual os seres humanos existem no capitalismo e define como as relações sociais se estabelecem na sociedade capitalista; vide, por exemplo, a relação desigual e contraditória entre trabalho-capital.

o preço, quando tomado em uma perspectiva naturalizada, por si só pouco explica por que um objeto custa x ou y. Daí a necessidade em se considerar o preço como expressão monetária do valor e esse último como processo às relações de produção no capitalismo e tudo o que ela contém.

Marx, ao tratar da relação entre valor de troca da mercadoria e dinheiro, explicita que o valor de troca sob a determinação do dinheiro é preço ou, em outros termos, a mercadoria possui um valor de troca, que não é preço, mas no decorrer do processo possui um preço (ROSDOLSKY, 2001). Somente quando nos debruçamos no processo, isto é, o processo do valor corporificado em um objeto (mercadoria) é que o preço passa a ter sentido. De acordo com Rosdolsky (2001, p.125):

No preço, o dinheiro se apresenta em primeiro lugar como a unidade de todos os valores de troca; em seguida, como unidade na qual esses valores são quantificados; por serem igualados ao dinheiro, eles podem expressar sua relação quantitativa recíproca. Nesse caso, o dinheiro atua como denominador universal, como medida de valores, como "o material em que o valor das mercadorias se expressa socialmente", é a forma necessária de manifestação da medida de valor imanente às mercadorias: o tempo de trabalho. Esta determinação resulta da lei geral do valor: como todas as mercadorias, inclusive o dinheiro, contêm trabalho humano objetivado, o valor de uma mercadoria [...].

Por mais simples que seja, a mercadoria produzida para outrem envolve um conjunto complexo de diferentes tipos de trabalho qualitativos e quantitativos para se realizar. $O$ trabalho despendido na produção de uma mercadoria, seja ela qual for, possui um duplo aspecto: o trabalho concreto e o trabalho abstrato. Ao nos debruçamos sobre a terramercadoria, a categoria trabalho na produção urbana é fundamental para se compreender o peso das localizações na cidade e como elas se relacionam com diferenciações dos preços entre os lugares, além daquilo que em nosso trabalho é de fundamental importância, a renda fundiária urbana ${ }^{14} \mathrm{e}$ o modo como clarifica o processo da obsolescência urbana.

Antes de refletirmos sobre terra-mercadoria, pensemos na diferença entre pastilha de freio de automóveis e chip de computador. Tanto a produção da pastilha quanto o chip abarcam inúmeros setores produtivos e etapas para que se constituam como mercadorias, envolvem um contingente de trabalhadores que executam diversas tarefas de produção. Em comum, pastilha e chip têm o fato de ambas serem mercadorias, ou seja, as duas são resultado do trabalho concreto (trabalho físico e mental específico que resulta na produção de uma mercadoria) e trabalho abstrato (tempo socialmente necessário para a produção) realizado e corporificado na 
mercadoria. O valor de uso de uma mercadoria, sua existência física só é possível na medida em que o trabalho concreto acontece.

A mercadoria só é portadora do valor de uso em função do trabalho concreto nela corporificado, porém, o trabalho concreto despendido na produção de uma pastilha e de um chip possuem distintas características e particularidades; portanto o quantum de trabalho concreto empregado na produção de ambas se difere, logo o valor dessas duas mercadorias também difere. A mesma lógica vale para o trabalho abstrato. Devemos considerar o tempo efetivo da produção de todos os componentes diretos ou indiretos na produção, isto é, desde matérias primas até o produto final, envolvendo amplo leque de relações e contradições sociais, em especial entre força de trabalho e capital, que vai da produção ao consumo das mercadorias.

Uma das matérias primas utilizada na produção da pastilha de freio e do chip é o quartzo, um abundante mineral da Terra. $\mathrm{O}$ trabalho abstrato na produção da pastilha $\mathrm{e}$ do chip são diferentes em qualidade, mesmo que ambos possuam como ponto de partida o quartzo (aqui é importante salientar que não se trata da qualidade no sentido de produto melhor ou pior, mas sim do sentido do valor agregado e diferencial que pastilha e chip contêm). $\mathrm{O}$ uso do quartzo enquanto matéria-prima tanto para um quanto para outro se difere no que tange às propriedades a serem obtidas, no caso, a pastilha necessita do silicato e o chip do silício.

Obter tais propriedades e processá-las até o produto final exige trabalhos concretos que por si só são diferentes e, ao mesmo tempo, demandam de trabalho abstrato, isto é, a especificidade do trabalho traduzida pela qualidade diferencial necessária ao longo da produção da pastilha e do chip. Para que seja diferencial, exige tipos específicos e distintos de trabalho determinados pelas qualificações dos trabalhadores, bem como pelos diferentes tipos de máquinas e tecnologias utilizadas na produção, sendo que tais máquinas e tecnologias em toda cadeia produtiva também são resultados do trabalho concreto e abstrato.

O trabalho abstrato contém trabalho concreto e vice-versa, e isso determina o valor de troca da mercadoria, ou simplesmente o valor da mercadoria. 0 que define a diferença do valor da pastilha e do chip, valor esse expresso pelo preço, é o tempo do trabalho socialmente necessário para se produzir um e outro. $\mathrm{O}$ tempo de trabalho social médio como processo determina o valor social da mercadoria, esse traduzido pelo preço.

O sistema capitalista oculta, de modo intencional, que custos e despesas envoltos nas mercadorias são frutos do trabalho realizado e corporificado nas mercadorias. Oculta também que a taxa de lucro e as demais formas de remuneração do capital são definidas não por outra condição que não seja a exploração da mais-valia. Ao trazer essa reflexão para o contexto da terra-mercadoria na realidade urbana, a sua dinâmica - o que envolve questões como valor, preços, localização, renda fundiária entre outros - tende a ser explicada de modo parcial ou com modelos muito bem elaborados que acabam por ocultar, de forma deliberada, que a lógica da terra-mercadoria é fundamentalmente determinada pela relação desigual e combinada entre capital-trabalho.

Por não ser resultado do trabalho, a terra não possui valor, mas possui preço, portanto é considerada como uma mercadoria sui generis. No caso da terra urbana, como unidade isolada, um lote $\mathrm{x}$, na medida em que o lote é incorporado ao processo de produção da cidade, além de ter o seu preço ampliado, se valoriza e atua também como elemento valorização do todo de um ambiente construído. Marx, no livro III do Capital, dedica parte das análises à questão do preço da terra, tomando como referência a terra 
agrícola, mas é possível transpor para a lógica da terra urbana. Segundo Marx (2017, p. 896):

É a renda fundiária [...] capitalizada que forma o preço de compra ou valor do solo, uma categoria que prima facie, exatamente do mesmo modo que o preço do trabalho, é irracional, já que a terra não é produto do trabalho e, por conseguinte, não possui valor nenhum.

Conforme asseveramos (GONÇALVES, 2015 e 2018), a renda fundiária (uma fração da mais-valia ou, mais precisamente, um componente particular e específico da maisvalia) se trata de um valor extraordinário apropriado sob a lógica do mercado de terras aos que detém a propriedade privada dessa mercadoria ou, nos termos precisos colocados por Oliveira (2007, p.43),

A renda da terra é uma categoria especial na Economia Política, porque ela é um lucro extraordinário, suplementar, permanente, que ocorre tanto no campo como na cidade. $O$ lucro extraordinário é a fração apropriada pelo capitalista acima do lucro médio [...]. Como ela é um lucro extraordinário permanente, ela é, portanto, produto do trabalho excedente [...] o trabalho excedente é a parcela do processo de trabalho que o trabalhador dá ao capitalista, além do trabalho necessário para adquirir os meios necessários à sua subsistência.

Esse lucro extraordinário trata-se de renda capitalizada, pois à medida em que os investidores e capitalistas compram a terra estão "convertendo o seu capital-dinheiro em renda capitalizada da terra, renda antecipada, ou seja, estão adquirindo o direito de extrair renda, mesmo naqueles lugares onde aparentemente ela pode não existir" (OLIVEIRA, 2007, p.63). Já na cidade a renda assume uma forma abstrata, "a renda não se apresenta mais como um produto do solo como ocorre no campo, ela aparece como nada mais que o juro de um capital investido" (BOTELHO, 2008, p. 26).

Além disso, "a renda da terra é determinada pelo uso socialmente estabelecido na organização da produção e circulação, paga ao proprietário, consequência do valor de troca, muitas vezes antecedida à determinação do uso por ações de especulação e escassez de localizações" (HARVEY, 1980, p.154).

Para Odette Seabra (1988, p. 100), a renda fundiária constitui-se numa categoria teórica exploratória e explicativa das especificidades dos lugares inscritos espacialmente e socialmente. Diz ela em relação à renda fundiária:

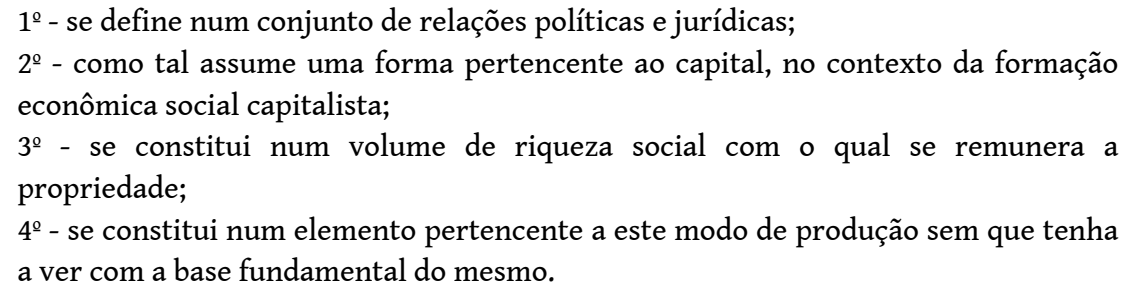

A terra e o trabalho passaram por diferentes modos de apropriação, entretanto é no modo de produção capitalista que esses dois conheceram atribuições distintas e específicas. $\mathrm{Na}$ atual sociedade tudo se produz e se reproduz na forma de mercadoria. Terra e trabalho são mercadorias distintas das outras, possuem leis particulares de reprodução, mas sujeitas na totalidade às leis de reprodução social. É no mundo da mercadoria, através dos valores de uso e de troca, que sujeitos e lugares se realizam historicamente.

De acordo com Carlos (1994: p, 85),

0 uso ligado a momentos particulares do processo de produção das relações capitalistas é o modo de ocupação de determinado lugar da cidade, a partir da 
necessidade de realização de determinada ação, seja a de produzir, consumir habitar ou viver. $\mathrm{O}$ ser humano necessita para viver, ocupar um determinado lugar no espaço. Só que o ato em si não é meramente o de ocupar uma parcela do espaço; ele envolve o ato de produzir o lugar.

47 A terra em si mesma não possui a propriedade de ser mercadoria, o que só ocorre mediante a formação do mercado de terras. Ao se tornar mercadoria, equivalente de trabalho ou a terra como trabalho, diz-se que se trata de uma mercadoria especial, pois possui características peculiares que nenhuma outra mercadoria tem. Tomando Harvey (1980: p. 135-6) como referencial, podemos inferir sobre as particularidades que marcam o solo urbano:

(a) O solo e as benfeitorias são fixos no espaço, não circulam, mas possuem localização, e devido a essa propriedade, proporciona ao seu detentor um monopólio, que lhe dá o direito de determinar o uso do espaço fixo, através da propriedade privada.

(b) Os homens não podem viver sem solo e benfeitorias, afinal, nossas realizações, nosso cotidiano, não se dá no plano abstrato. $O$ solo e as benfeitorias são condições essenciais, por exemplo, para morar, trabalhar, circular etc.

(c) "O solo e as benfeitorias mudam de mãos relativamente com pouca frequência (...)".

(d) "O solo é algo permanente, e a probabilidade de vida das benfeitorias é muitas vezes considerável. $\mathrm{O}$ solo e as benfeitorias, e os direitos de uso a elas ligados, por isso, propiciam a oportunidade de acumular riqueza tanto para os indivíduos como para a sociedade (...). Numa economia capitalista um indivíduo tem um duplo interesse na propriedade, ao mesmo tempo como valor de uso atual e futuro e como valor de troca potencial ou atual, tanto agora como no futuro".

(e) "A troca no mercado ocorre em um momento do tempo, mas o uso se estende por um período de tempo".

(f) "O solo e as benfeitorias têm usos diferentes e numerosos que não são mutuamente exclusivos para o usuário".

Ainda de acordo com Harvey, tomados em conjunto, esses usos em relação ao solo e suas benfeitorias se tornam valor de uso e dialeticamente valor de troca.

Essa dupla propriedade do solo e suas benfeitorias serão determinadas de acordo com os interesses dos seus detentores. Para o proprietário pode ser valor de uso à medida em que ele a utiliza para morar ou para desenvolver um tipo de atividade econômica. Pode também o proprietário ser locador e daí obter renda. Logra também, possuindo ou não edificação no solo especular no mercado de terras, ao aguardar o melhor momento para realizar o valor de troca.

Há também outros agentes que trabalham e interferem de modo acentuado no uso do solo e o alteram continuamente ao longo do tempo. Corretoras de imóveis atuam no mercado de terra para obter valor de troca através da compra, venda ou da cobrança de transações imobiliárias. Incorporadoras e construtoras operam no mercado de terra criando valores de usos (residenciais ou comerciais, por exemplo) para obter parte do processo de valorização em curso. Instituições financeiras também atuam no mercado fundiário financiando empreendimentos de forma direta, disponibilizando cartas de créditos aos consumidores ou criando fundos de investimentos, consórcios etc. Por último, as instituições pertencentes à esfera governamental, por meio de políticas habitacionais, produzem valores de uso relacionados à moradia. Em países como o Brasil, com políticas habitacionais voltadas à produção de moradias populares, o resultado é perverso, pois a produção de moradias na maior parte das vezes ocorre 
longe das regiões centrais das cidades, o que contribui para o aumento significativo de áreas periféricas e para a vulnerabilização da classe trabalhadora mais pobre.

51 No interior do espaço-mercadoria, os lugares como valor de troca se realizarão ao incorporarem ou não trabalho social, fundamentalmente em função do volume e riqueza social (valores de uso) criados. Nesse sentido, de acordo com Seabra (1988, p. 100):

o espaço-função de "n" lugares - tem um valor que lhe corresponde em função da produção social, um valor genérico (valor de uso) que se expressa num preço (expressão formal do valor de troca) o qual é primeiro equivalência da produção social para ser também, eventualmente, um valor agregado, acrescido por tributos próprios do lugar. Nesse sentido, o espaço é também objeto.

O processo de produção e reprodução capitalista valoriza a terra na forma de propriedade, onde a renda que se obtém a partir das leis de reprodução é um meio de captação da mais-valia da riqueza da sociedade. 0 espaço, inicialmente convertido pelo seu vetor utilitário em valor de uso à sociedade, no decorrer do processo histórico social se torna prisioneiro das condições de produção e reprodução capitalistas.

Na realidade da cidade capitalista, o valor de troca tem se sobreposto ao valor de uso. Isso significa que para usar o lugar é necessário que antes se realize o valor de troca. Por isso o processo de valorização do espaço sob a égide das relações capitalistas de produção passa necessariamente pela mercantilização dos lugares. A relação que se trava nos lugares, portanto, são também automaticamente mercantilizadas.

Em relação à cidade capitalista, Odette Seabra $(1988$, p.102) nos fala que

o processo de valorização na circunstância histórica do capitalismo é o processo que vai pondo, gradativamente, os diferentes lugares da Terra - como localização, como recurso - sob a vigência das leis abstratas da reprodução social, no qual a terra vai se constituindo em força produtiva da sociedade, assumindo a condição de capital social. A virtualidade deste processo está em tornar social o espaço mesmo, ainda que sob a vigência da propriedade privada da terra. De tal forma que a socialização do espaço e a privatização do espaço são faces contraditórias de um mesmo processo que ao se desenvolver cria a cidade capitalista.

55 À medida em que o espaço urbano se reproduz sob a lógica do processo das leis de mercado, esse se torna suporte das atividades produzidas pela sociedade. Os usos da terra urbana são os mais variados possíveis: industrial, comercial, serviços, residenciais etc. Porém as localizações dessas atividades não são de modo algum caóticas ou aleatórias, elas obedecem a uma ordem, a uma geografia absolutamente ordenada, segundo os preços de mercado. Tomemos que o espaço urbano é muito mais que um lugar onde se desenrola o cotidiano da sociedade, é mais do que o ato de viver, morar, trabalhar, interagir nas mais variadas situações, é mais do que um lugar em que se alocam atividades econômicas.

O espaço urbano é em si mesmo não apenas o espaço dos conflitos, da produção e (re)produção de relações de todas as ordens e instâncias - social, política, cultural e jurídica - mas também o lócus da (re)produção do capital, da extração de lucros, rendas, juros. É marcado pelo "jogo" desigual entre as classes sociais. É um espaço sobre o qual incide as determinações do capital. o capital passa a comandar e determinar os possíveis usos dos lugares, das localizações, das atividades de todas as ordens, em síntese, da realidade como um todo. Nessa luta, não há passividade dos sujeitos, acirram-se os conflitos em que a vida imediata (o caminhar, o morar, o respirar etc.) está sujeita aos interesses econômicos. 
57 A apropriação privada da terra por parte dos capitalistas tem sido condição primordial para sua (re)produção. É no processo de apropriação privada da terra por parte desses sujeitos que se colocam em contraste a cidade como valor de uso e a cidade como valor de troca.

Para que ocorra de modo concreto a produção, a circulação, a troca e o consumo na cidade, faz-se necessário construir, produzir espaços e localizações capazes de assentarem os usos técnicos na terra - indústrias, bancos, prédios comerciais e residenciais, casas comerciais. Porém esse construir, esse alocar usos técnicos na terra significa também ter disponibilizado o suporte das vias de circulação e comunicação, da infraestrutura como um todo. Aqui surge o Estado no processo de (re)produção do espaço urbano.

59 As localizações produzidas não são dotadas dos mesmos conteúdos, dos mesmos ou similares usos técnicos. Independentemente da localização produzida no espaço, ela gera aglomeração tanto de objetos técnicos como de pessoas; mas dadas as estratégias e interesses do mercado fundiário gestam-se espaços diferenciados, uns dotados das máximas condições de vida social e econômica, enquanto outros são isolados e marginalizados, vivem na penúria em todos os âmbitos da vida.

Como afirmado, as localizações não são aleatórias e só podem ser compreendidas na totalidade determinada pelo movimento social e histórico que marca o urbano. Entretanto o uso da terra no espaço urbano não é imutável, pois o movimento social e histórico é contínuo, traz no decorrer do tempo uma metamorfização ao espaço e altera sua dimensão, sua forma, seu conteúdo e seu cotidiano propriamente dito.

61 O espaço urbano expressa a lógica da divisão social e territorial do trabalho e disto derivam os conflitos que permeiam a realidade da sociedade. Apreender o urbano necessariamente obriga-nos a debruçar sobre a totalidade dos fenômenos e eventos que determinam sua dinâmica. A realidade urbana determinada pelo modo de produção capitalista transcende a esfera da produção econômica, pois a economia é política e é só nessa perspectiva que interessa considerá-la.

Os preços diferenciais da terra podem ser compreendidos de acordo com o ambiente construído e os usos do espaço que se processam na atualidade. Entretanto, o ambiente construído e os usos do solo não são imutáveis no tempo e no espaço, logo os preços expressam a sobreposição das condições passadas, presentes e futuras na dinâmica fundiária urbana. Desse modo, toma-se como premissa o fato de que há inúmeras escalas espaciais e temporais de análise para se compreender a formação de preços em uma determinada área ou bairro, bem como as variações internas desses preços nesses ambientes. Há em Harvey ${ }^{15}$ uma clarificação sobre a relação entre o ambiente construído e o preço, diz ele:

Os preços formam o que reflete as condições da produção em diversos lugares em condições variadas de trabalho concreto. O processo da troca está, em suma, eternamente se abstraindo das especificidades do lugar por meio da formação do preço. Isso pavimenta o caminho para a conceituação dos valores independem do lugar. O trabalho abstrato incorporado em lugares particulares sob condições concretas específicas é uma média social extraída de todas as localizações e condições.

Diante dessa complexidade explicitamos o seu contrário, no caso, a lógica dos preços dos imóveis sob a perspectiva do mercado imobiliário, que adota os princípios da teoria do valor utilidade. A título de exemplo, em matéria veiculada pelo jornal o Estado de 
São Paulo, intitulada "Quando dois mais dois podem não ser quatro: a avaliação imobiliária é uma metodologia complexa, com variáveis subjetivas”, o autor procura demonstrar didaticamente quais os elementos que o mercado imobiliário trabalha quando se trata da questão do preço na realidade do ambiente construído da cidade. Diz a matéria ${ }^{16}$ em seus fragmentos:

Calcular o preço de um imóvel pode ser um árduo exercício. "O preço sempre será resultado do desejo de duas pessoas, do vendedor e do comprador" [...] Portanto, nesta conta, dois mais dois pode nunca ser igual a quatro.

Avaliações

A perita Angela dos Santos Silva, do Secovi ensina, [...] a fazer o cálculo utilizado nas avaliações oficiais, embora alerta que o resultado ainda não será o real. "Faça a pesquisa do preço do terreno no bairro em que está o imóvel, depois calcule o preço de custo de construção do imóvel, que chamamos benfeitoria, e some o resultado ao preço do terreno."

Para calcular o preço de custo de benfeitoria multiplique a metragem do imóvel por um dos índices utilizados pelo mercado. 0 mais comum é o Custo Unitário Básico (CUB), calculado pela Fundação Getúlio Vargas para o Sindicato da Construção (SindusconSP). Há, ainda, o Sinapi, do Instituto Brasileiro de Geografia Estatística (IBGE). Os dois podem ser encontrados nos sites das instituições [...].

O diretor de estudos especiais da Empresa Brasileira de Estudos do Patrimônio (Embraesp), Luiz Paulo Pompéia, ressalta, no entanto, que esta fórmula não inclui o lucro nem o custo de comercialização, que também são itens que compõem o preço de um imóvel. "O custo de comercialização é a corretagem, que em imóveis novos é de $3,5 \%$ a $6 \%$. Nos usados, é de $6 \%$."

Em imóveis novos é preciso acrescentar ainda o custo do marketing (6,5\%) e o lucro do empreendedor. "Quando se questiona preços, sempre se reclama do preço do terreno e dos custos de construção, mas ninguém fala do lucro", diz. Segundo Pompéia, o mercado trabalha com uma margem de lucro mínima igual ao valor pago pelo terreno. Considerando que o preço do terreno corresponde de $10 \%$ a $20 \%$ do valor do imóvel, esta é a margem de lucro praticada atualmente. "Em alguns casos, especialmente em imóveis de alto luxo, é ainda maior".

Especificidades

Por exemplo, numa rua pode haver predominância de imóveis comerciais de um lado e residenciais do outro. "Se o imóvel estiver na área comercial, vai valer menos". No caso de apartamentos, o andar também faz mudar o preço entre unidades iguais. "Até mesmo o tipo de comprador pode alterar o preço" (...) A incidência de luz solar e da vista também influem. "Se estiver virado para o fosso interno, por exemplo, ou para a face sul, ou no primeiro andar, também vale menos e a venda é mais demorada.

64 Abordagens expressas nos depoimentos tratam dos denominados preços hedônicos ${ }^{17}$ ou preços implícitos, onde "os bens são medidos pelas características que se mostram relevantes para a escolha das pessoas, e o consumidor exerce preferências, maximizando utilidade" (ARRAES \& FILHO, 2008, p. 292). O preço da terra e dos imóveis se dá em função de características vinculadas a três vetores preliminarmente primordiais:

Atributos físicos do bem, vizinhança ou localização ótima e características ambientais inerentes ao imóvel [...]. O capital imobiliário envida estratégia de ação para realização de ganhos fundiários, traduzindo-se em externalidades incorporadas aos preços dos imóveis e definindo escolhas de famílias com diferentes rendas (ARRAES \& FILHO, 2008, p. 290).

65 Para exemplificar os elementos e fatores considerados na composição dos preços dos imóveis a partir da lógica dos preços hedônicos, temos o seguinte esquema (figura 2) produzido por Arraes \& Filho (2008), que em um estudo de caso, tratam dos 
determinantes econômicos e externalidades no processo de formação de preços na capital do Estado do Ceará: Fortaleza.

Figura 2- Modelo econômico-financeiro de preços hedônicos

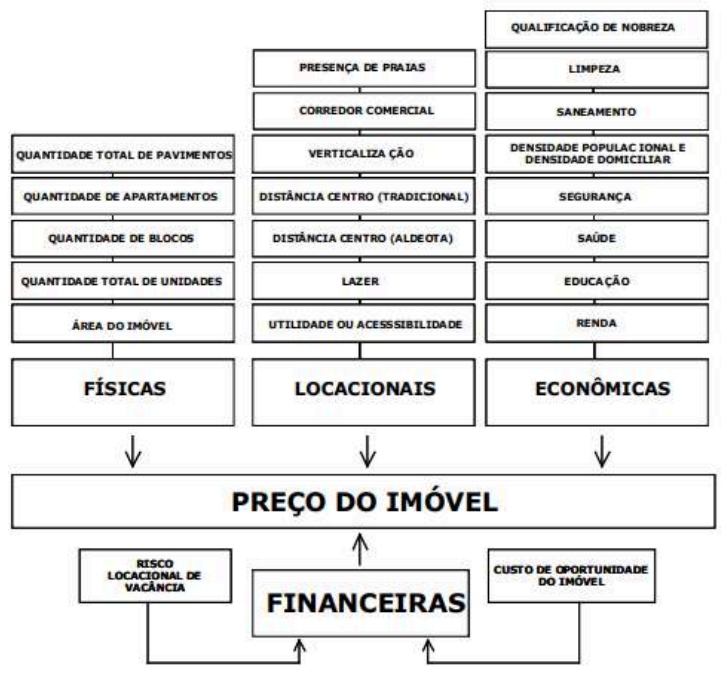

Fonte: Arraes \& Filho (2008)

Não há como desconsiderar os modelos relativos aos fatores físicos dos imóveis levados em conta pelo mercado na determinação dos preços. Porém é fundamental considerar nos termos de Harvey (2013, p.436) que:

[...] os preços formam o que reflete as condições da produção em diversos lugares em condições variadas de trabalho concreto e que o processo de troca está, em suma, eternamente se abstraindo das especificidades do lugar por meio da formação do preço [...] pavimenta o caminho para a conceituação dos valores independente do lugar, isto é, o trabalho abstrato incorporado em lugares particulares sob condições concretas específicas é uma média social extraída de todas as localizações e condições.

Essa assertiva de Harvey ${ }^{18}$ coloca em xeque a simplificação ou ocultação de dois fatores: 1) "o preço sempre será resultado do desejo de duas pessoas, do vendedor e do comprador ${ }^{19 "}$; e 2) No preço final do imóvel deve se acrescer a porcentagem da corretagem e, no caso dos imóveis novos, o custo do marketing e a taxa de juros do empreendedor.

68 No mercado de terras há um embate, pois cada sujeito, vendedor e comprador, desempenham "papéis" específicos, ademais o preço não está relacionado à produção da terra.

Quando se trata da venda de novas edificações deve-se considerar toda uma cadeia envolvida no processo de produção de uma edificação em que cada agente econômico envolvido vislumbra para si obter valores de troca expressos nas formas de remuneração do capital: os juros, o lucro e a renda. Mas a composição do preço de um imóvel ou de uma terra nua na cidade não pode ser desarticulado do ambiente construído onde ele está situado.

Por ambiente construído consideramos que vai além da sua forma física propriamente dita. 0 ambiente construído na realidade urbana só ganha sentido geográfico na medida em que o consideramos na sua totalidade como uma expressão da fisionomia relativa à 
configuração territorial da cidade, suas áreas, seus bairros, formados por objetos de todas as ordens produzidos pela sociedade, pelo Capital e pelo Estado - tal como nos ensina Milton Santos (1999).

71 Nessa perspectiva, ao associarmos o ambiente urbano construído à configuração territorial, ambos decorrentes da dinâmica ou produção espacial capitalista, compreendemos que ele traduz a obsolescência urbana. Isso ocorre, pois tal processo é fomentado nos interstícios do modo combinado, desigual e contraditório como cada segmento presente na realidade da cidade (o que engloba os agentes econômicos privados, o Estado e os demais segmentos e instâncias da sociedade) exerce seus mecanismos de controle, ordenamento, conflitos, ganhos e perdas, suas intenções presentes e futuras, no que tange à disputa pelos usos (valores de uso e valores de troca) da terra urbana.

De acordo com Girardi (2008, p.36), "a intensidade e a forma da ação de poder (exercidos pelos segmentos presentes na cidade) nas diferentes dimensões do espaço originam diferentes tipos de territórios". Nesse sentido, os diferentes territórios na cidade de São Paulo expressam diferentes ambientes construídos, marcados por múltiplos usos da terra urbana e por um conjunto de objetos específicos e gerais, que possuem na sua totalidade, enquanto territórios constituídos, a finalidade de servirem como elementos fundamentais ao processo de reprodução do capital e da força de trabalho na cidade; mesmo que isso se dê nas contradições e nos movimentos desiguais da produção da cidade.

73 Além disso, os diferentes tipos de territórios na cidade abrigam um conjunto amplo de equipamentos pertencentes ao Estado (federal, estadual e municipal), que distribuídos de modo desigual no espaço urbano, atuam em diferentes escalas de intensidade na realidade social e econômica de São Paulo e, ao mesmo tempo, de maneira articulada ao capital contribui para as diferenciações sociais e econômicas vivenciadas por toda a população no espaço urbano paulistano.

Tal condição implica e reforça que alguns segmentos da população, direta ou indiretamente, tendem a se beneficiar mais em detrimento de outros. Isso vale para questões relativas ao que se pode chamar de qualidade de vida, bem como aos processos de maior ou menor valorização das propriedades privadas da terra.

$\mathrm{Na}$ comunicação $\mathrm{o}^{20}$ entre distintos objetos geográficos produzidos por diversos agentes e marcados por formas, estruturas e funções específicas, é que eles (os objetos) justificam suas existências na realidade espacial urbana, formando um sistema de objetos. Entretanto, esse vínculo possui diferentes graus na medida em que os objetos ou os sistemas de objetos presentes na cidade são concebidos de acordo com a lógica da divisão técnica e social do território que se impõe na realidade urbana.

Goldenstein \& Seabra (1982) lembram que o desenvolvimento das atividades econômicas não se dá de maneira uniforme entre os diversos ramos e seus setores, além disso, historicamente, há sob o capitalismo a existência de formas avançadas de divisão do trabalho e a permanente redefinição das proporções e do significado social e territorial desta divisão.

77 Para Lipietz (1977 apud GOLDENSTEIN; SEABRA, 1982) é possível levar em conta duas formas de divisão do trabalho social quando nos reportarmos ao território: uma divisão horizontal que se dá entre os diferentes ramos de atividades econômicas atuantes na cidade e uma divisão vertical entre grupos sociais - dominantes e dominados - os que 
possuem os meios de produção, no caso os capitalistas e os que não os possuem, ou seja, os trabalhadores, também marcados como classe social pela não uniformidade de suas funções, atividades exercidas e remunerações recebidas.

Desse modo, para Lipietz ${ }^{21}$ temos uma relação dialética onde na divisão horizontal está contida a uma divisão vertical, o que leva a divisão social e técnica do trabalho a ter uma dimensão territorial, porém desigual e combinada; o que notadamente em uma cidade como São Paulo, expressa uma diferenciação espacial significativa, marcada por áreas e bairros, que em uma escala vão de conteúdos ou ambientes construídos altamente modernos a ambientes construídos extremamente obsoletos.

Na medida em que alguns objetos não conseguem desempenhar funções para os quais foram criados, tendem a ter seus conteúdos alterados, substituídos por outras funções ou simplesmente serem eliminados - isso considerando que os objetos e infraestruturas construídas, ao menos em tese, são produzidas para durar por um longo tempo.

80 Cidades como São Paulo e os bairros que as compõem não envelhecem, mas muitos lugares envelhecem precocemente, pois o ambiente construído definido pelas mais diversas tipologias construtivas e infraestruturas estão em constante estado de transformação. Não por se tratar de um dado natural ou porque simplesmente envelhecem, mas sim por ser um processo inerente à lógica e às exigências do capitalismo, que demanda para sua própria existência a condição de destruir ou redefinir as formas, funções e conteúdos conforme eles não mais servem para sua reprodução $0^{22}$.

Destruir, manter e redefinir os objetos que formam o ambiente construído na cidade são ações fundamentais para garantir aos agentes econômicos diversas formas de remuneração: no caso, o lucro, o juro e a renda.

82 Também é condição importante para garantir ao Estado - nas três esferas de poder, a saber: federal, estadual e municipal - os impostos e tributos cobrados, revertidos e aplicados de maneira seletiva entre as diferentes áreas e territórios da cidade.

Em suma, os ambientes construídos que se tornam obsoletos são aqueles que não conseguem mais remunerar de modo satisfatório aquilo que é exigido pela lógica do capital, isto é, a acumulação e remunerações de capitais para os agentes capitalistas que produzem o espaço urbano.

O processo da industrialização-urbanização em um passado não muito distante ditava efetivamente a dinâmica espacial da cidade, ao mobilizar vultosos capitais de todas as ordens, tanto de agentes privados, quanto do Estado (em nível federal, estadual e municipal), além de uma massa exponencial de força de trabalho.

$\mathrm{Na}$ atual fase da cidade o setor financeiro, bancário, de crédito e o setor terciário moderno são agentes primordiais no processo de urbanização, exigindo e imprimindo continuamente de modo selecionado alterações nos ambientes construídos para dar sustentação a seus interesses, em especial, na acumulação de capitais.

Há que se considerar que os objetos presentes na cidade nos tempos atuais - em função de suas mais variadas escalas determinadas pelas suas formas, conteúdos e funções, bem como pelas suas localizações - possuem caráter relativo, isto é, um conjunto de objetos consegue se comunicar entre si com maior eficiência do que outros. Logo, podemos falar em uma obsolescência técnica e socialmente determinada dos objetos 
que não conseguem cumprir as exigências determinadas pelos setores modernos presentes no sistema capitalista e que se espacializam na cidade.

Essa condição seria suficiente para responder pelo processo da obsolescência espacial urbana? Entendemos que não. Os ambientes construídos e seus respectivos usos, pretéritos e presentes, só podem ser compreendidos na medida em que consideramos os propósitos dos diversos agentes que formam a sociedade. Os agentes econômicos privados e o Estado, historicamente em ações combinadas e contraditórias, constroem, destroem e reconstroem diferentes ambientes ou territórios na cidade de São Paulo, o que implicou na determinação e alteração dos valores de uso ligados à terra urbana, sobretudo, ao redimensionar valores de troca.

Em que pese a repetição, trata-se o ambiente construído na sua totalidade constituído por objetos geográficos, como nos diz Milton Santos (1999), ou pelos mais elementos diversos como nos assevera David Harvey (2013, p. 315), uma longa e infinita lista composta por fábricas, casas, prédios, lojas, armazéns, rodovias, ruas, avenidas, hidrelétricas, sistemas de fornecimento de água e coleta de esgoto, escolas, cinemas, teatros, parques, hospitais, autarquias e órgãos públicos e privados das mais diversas ordens; em suma, uma listagem interminável ${ }^{23}$.

Porém, o ambiente construído vai além de uma listagem ou de características apontadas até aqui, isto é, para que possamos articulá-lo ao fator preço devemos considerá-lo ainda como um capital fixo imóvel, o qual, nos dizeres de Harvey, funciona como um vasto recurso que compreende valores de uso incorporados no ambiente construído e utilizados pelo capital conforme suas necessidades para a produção, a troca e o consumo.

90 Além disso, deve-se anotar que os valores de uso do ambiente construído a partir da ótica da produção podem ser considerados tanto do ponto de vista das condições gerais de produção quanto das forças diretas da produção. Isso implica, quando se considera o ambiente construído como capital fixo, que melhorias e renovações na terra urbana são necessárias sob a ótica do processo de ampliação do capital.

91 Essa realidade não pode ser outra, afinal as forças produtivas no sistema capitalista, bem como a terra urbana e tudo o que ela contém, demandam de constantes ações revolucionárias e ressignificações que potencializam a produção propriamente dita no sentido de, pelas mãos do sistema financeiro, intensificar a troca e o consumo dos valores de uso.

\section{Considerações finais}

Os elementos ou objetos do ambiente construído e todas as partes que o constitui, na medida em que ele vai sendo formado, de acordo com Harvey ${ }^{24}$ "têm uma posição ou localização espacial como atributo mais fundamental do que incidental". Desse modo, os elementos que são alocados ou produzidos (valor de uso) devem ser ou ficar reunidos de forma integrada ao conjunto espacial de um dado lugar, de tal maneira que garantam aos seus proprietários um retorno significativo a partir do arrendamento a terceiros dos valores de uso que esses elementos possuem ou uma valorização de suas propriedades.

Os elementos que compõem o ambiente construído se dão em diferentes tempos e espaços, considerando aqui a escala de um bairro ou localidade. A produção, o modo 
como são dispostos, suas manutenções, renovações, alterações, possuem dilemas como nos assevera Harvey, pois os elementos individuais que pertencem aos seus proprietários devem nessas ações fazer com que suas mercadorias assumam uma configuração apropriada onde estão localizadas. Caso isso não ocorra a contento sob a lógica do mercado fundiário, as interferências nos preços praticados (compra, venda e locação) podem ser séria e negativamente afetados e quadros de obsolescência espacial podem se instalar no ambiente.

94 A regulação do ambiente construído vai além dos proprietários individuais. Tanto o Estado quanto o mercado fundiário (esse cada vez mais controlado pela esfera financeira) também desempenham ações significativas nesse processo, sobretudo no que diz respeito ao planejamento do uso do solo e na constituição de novos valores de uso, sejam eles constituídos de bens privados ou públicos.

Caso nenhum dos três agentes envolvidos nos processos de construção do ambiente façam os investimentos necessários ao longo do tempo, o ambiente ou suas parcelas acabam por ter seus preços depreciados face a outros ambientes que foram alvos de investimentos. A consequência disso é a formação de áreas e setores obsoletos fisicamente, tecnicamente e economicamente.

Tanto os ambientes construídos que se mantém geograficamente satisfatórios sob a lógica do mercado de terras, quanto aqueles que caminham ou possuem realidade inversa aos primeiros, imprimem aos elementos ou objetos constituintes desses ambientes um preço, sejam eles relativos aos aluguéis praticados dos antigos elementos (comercial, residencial, industrial e outros), sejam eles relativos ao preço de produção de novos ambientes.

Por tratar-se de um capital fixo imóvel, o ambiente construído não difere da lógica pertinente de outros capitais fixos, em especial aqueles da esfera da produção industrial, ou seja, de acordo com Harvey ${ }^{25}$, quanto maior o tempo de durabilidade desse capital, maior a probabilidade em incorrer sua desvalorização por meio de alterações tecnológicas.

No caso do ambiente construído, além do fator tecnológico das edificações, temos também a posição econômica no qual esse ambiente está localizado. Se essa posição ou localização para o conjunto dos agentes econômicos (e isso inclui os do setor imobiliário) consegue atender as demandas das remunerações do capital, ele tende sempre a cada vez mais se valorizar; caso contrário ocorre a desvalorização e, associado a essa condição, o processo da obsolescência espacial.

\section{BIBLIOGRAFIA}

ARRAES, Ronaldo A.; FILHO, Edmar de Sousa. Externalidades e formação de preços no mercado imobiliário urbano brasileiro: um estudo de caso. Economia Aplicada. Ribeirão Preto, vol.12 no.2, pp. 289-319, 2008. 
BOTELHO, Adriano. A renda fundiária urbana: uma categoria de análise ainda válida. GEOgraphia, Vol. 10, nº 19, 2008.

CAMPOS, Rodger Barros Antunes. O mercado imobiliário residencial no município de São Paulo: uma abordagem de preços hedônicos espacial. Belo Horizonte: Nova econ. vol.27 no.1 Jan./Apr. 2017.

CARLOS, Ana Fani Alessandri. O Espaço Urbano: Novos Escritos sobre a Cidade. São Paulo: Labur Edições, 2007.

GIRARDI, Eduardo Paulon. Proposição teórico-metodológica de uma cartografia geográfica crítica e sua aplicação no desenvolvimento do atlas da questão agrária brasileira. Tese de Doutorado apresentada ao Programa de Pós-Graduação da Faculdade de Ciências e Tecnologia da Universidade Estadual Paulista. Presidente Prudente: UNESP, 2008. 349 f.

GOLDENSTEIN, Lea; SEABRA, Manoel. Divisão territorial do trabalho e a nova regionalização. Revista do Departamento de Geografia - Universidade de São Paulo, São Paulo, pp. 21-47, 1982.

GONÇALVES, André Vinícius Martinez. O processo da obsolescência espacial urbana. Salvador: GeoTextos, vol. 16, n. 1, julho 2020

. Teoria da localização, teoria da renda fundiária urbana e o processo da obsolescência espacial urbana. Rio de Janeiro: Espaço e Economia [Online], Ano VII, número 13, 2018.

Obsolescência Espacial Urbana: O Ambiente Urbano de Santana em São Paulo - SP. Tese de Doutorado apresentada ao IGEO/IGE da UNICAMP, 2015.

Manifestações e contradições da metrópole de São Paulo no antigo Bairro de Santana - a paisagem, o valor da terra, a intervenção urbana e o fenômeno da deterioração urbana. Dissertação de Mestrado apresentada à Faculdade de Filosofia, Letras e Ciências Humanas - Departamento de Geografia da Universidade de São Paulo, 2006.

HARVEY, David. Os limites do capital. São Paulo: Boitempo, 2013. 591 p. . O trabalho, o capital e o conflito de classes em torno do ambiente construído nas sociedades capitalistas avançadas”. São Paulo: Espaço e Debates, n.6, 1982.

A Justiça Social e a Cidade. São Paulo: HUCITEC, 1980.

JORNAL FOLHA DE SÃO PAULO. São Paulo Ociosa. Disponível em: <https:// www1.folha.uol.com.br/especial/2017/sp-ociosa/>. Acesso em: 03 de novembro de 2020.

MARX, Karl. O Capital: Crítica da Economia Política. Livro III: O processo global da produção capitalista. São Paulo: Editora Boitempo, 2017.

. O Capital: Crítica da economia política. Livro I: O processo de produção do capital. São Paulo: Editora Boitempo, 2013.

. O Capital: crítica da economia política; Livro I. 23ª ed. Rio de Janeiro: Civilização Brasileira, 2006.

. O capital - crítica da economia política / vol. I - Livro primeiro: O processo de produção do capital. São Paulo: Coleção “Os Economistas”, Editora Nova Cultural Ltda, 1996. 473 p.

NOBRE, Eduardo Alberto Cuscé. Entre a preservação total e a renovação de mercado? Os conflitos do Bairro da Mooca no início do Século XXI. São Paulo: III Encontro da Associação Nacional de 
Pesquisa e Pós-graduação em Arquitetura e Urbanismo arquitetura, cidade e projeto: uma construção coletiva, 2014.

OLIVEIRA, Ariovaldo Umbelino de. Modo de produção capitalista, agricultura e reforma agrária. São Paulo: FFLCH/Labur Edições, 2007.

PREFEITURA MUNICIPAL DE SÃO PAULO. Operações Urbanas. Disponível em <https:// gestaourbana.prefeitura.sp.gov.br/estruturacao-territorial/operacoes-urbanas/>. Acesso em: 25 de novembro de 2020.

. Lei Municipal nº 16.050, de 31 de julho de 2014 / Decreto ํㅜ 56.589, de 10 de novembro de 2015. Disponível em:< https://www.prefeitura.sp.gov.br/cidade/secretarias/ urbanismo/funcao_social_da_propriedade/index.php?p=206523>. Acesso em: 22 de fevereiro de 2018.

PRIMI, Lilian. Quando dois mais dois podem não ser quatro: a avaliação imobiliária é uma metodologia complexa, com variáveis subjetivas. Jornal O Estado de São Paulo, 2010. Disponível em: <http://economia.estadao.com.br/noticias/economia,quando-dois-mais-dois-podem-naoser-quatro,39227,0.htm $\geq$. Acesso em: 22 de fevereiro de 2018.

RAMOS, Aluísio Wellichan. A cidade como negócio: aspectos da atuação do setor imobiliário e da relação público-privado na Barra Funda e na Água Branca (Município de São Paulo) - um exame crítico da operação urbana Água Branca e do projeto 'Bairro Novo'. Tese de Doutoramento apresentada à Faculdade de Filosofia, Letras e Ciências Humanas - Departamento de Geografia da Universidade de São Paulo, 2006.

ROSDOLSKY, Roman. Gênese e estrutura de o Capital de Karl Marx. Rio de Janeiro: EDUERJ: Contraponto, 2001.

SANTOS, Milton. A natureza do espaço - Técnica e tempo. Razão e emoção. São Paulo: Hucitec, 1999. $260 \mathrm{p}$.

Pensando o espaço do homem. São Paulo: Edusp, 2004. 90 p.

SCHUMPETER, Joseph A. Capitalismo, Socialismo e Democracia. Rio de Janeiro: Editora Fundo de Cultura, 1961.

SEABRA, Odette Carvalho de Lima. Pensando o processo de valorização e a geografia. São Paulo: Boletim Paulista de Geografia, nº 66, 1988.

SILVA, Eduardo. São Paulo tem déficit de 474 mil moradias, diz estudo. Disponível em: <https:// www1.folha.uol.com.br/cotidiano/2019/09/sao-paulo-tem-deficit-de-474-mil-moradias-dizestudo.shtml>. Acesso em 06 de novembro de 2020.

SINGER, Paul. Curso de introdução à economia política. Rio de Janeiro: Forense-Universitária, 1987.

SMITH, Neil. The new urban frontier. Gentrification and the revanchist city. Londres: Routledge, 1996.

\section{NOTAS}

1. Gonçalves, 2006.

2. Sobre as operações urbanas vigentes na cidade de São Paulo, consultar: https:// gestaourbana.prefeitura.sp.gov.br/estruturacao-territorial/operacoes-urbanas/.

3. Consultar Nobre, 2014. 
4. Aqui defendemos que se faz necessário a ideia de defesa da função social do uso da terra urbana e não da propriedade, visto que a edificação ou um terreno, expressão da propriedade, é um dos elementos, um dos capitais fixos em um determinado território. Militar em defesa da função social de uso da terra urbana é defender a cidade como direito, que vai muito além da questão da propriedade.

5. Lei Municipal nº 16.050, de 31 de julho de 2014 / Decreto $n^{\circ}$ 56.589, de 10 de novembro de 2015 . Consultar: https://www.prefeitura.sp.gov.br/cidade/secretarias/urbanismo/ funcao_social_da_propriedade/index.php?p=206523.

6. O jornal Folha de São Paulo disponibiliza no endereço eletrônico https:// www1.folha.uol.com.br/especial/2017/sp-ociosa/ um conjunto de matérias sobre edificações ociosas e abandonadas na cidade de São Paulo.

7. 0 termo déficit habitacional somente reforça que a política habitacional no Brasil demanda de urgente discussão, pois reduz a problemática habitacional à produção, acesso e consumo da mercadoria moradia e não ao direito à moradia, ao direito ao uso da terra urbana na sua totalidade. Devemos considerar que a maior demanda pelo morar de modo digno diz respeito à classe trabalhadora mais pobre que mal consegue realizar de modo decente três refeições diárias.

8. Em 2019, segundo a Fundação Getúlio Vargas, "na capital paulista, seriam necessárias 474 mil moradias populares para zerar esse índice". Consultar https://www1.folha.uol.com.br/cotidiano/ 2019/09/sao-paulo-tem-deficit-de-474-mil-moradias-diz-estudo.shtml.

9. Nesse trabalho foram consultadas três versões em português do Capital Livro I. A primeira publicada pela Editora Nova Cultural - Coleção Os Economistas em 1996, a segunda publicada pela editora Civilização Brasileira em 2006 e a terceira pela Editora Boitempo em 2013. Esse processo foi necessário dadas algumas diferenças nas traduções do texto original do Capital Livro I.

10. "Como criador de valores de uso, como trabalho útil, [...] é uma condição de existência do homem, independente de todas as formas de sociedade, eterna necessidade natural de mediação do metabolismo entre homem e natureza e, portanto, vida humana" (MARX, 1996, p.172).

11. Segundo Marx (1996, p. 188), "Quando no início deste capítulo, para seguir a maneira ordinária de falar, havíamos dito: A mercadoria é valor de uso e valor de troca, isso era, a rigor, falso. A mercadoria é valor de uso ou objeto de uso e "valor". Ela apresenta-se como esse duplo, que ela é, tão logo seu valor possua uma forma rápida de manifestação, diferente da sua forma natural, a do valor de troca, e ela jamais possui essa forma quando considerada isoladamente, porém sempre apenas na relação de valor ou de troca com uma segunda mercadoria de tipo diferente. No entanto, uma vez conhecido isso, aquela maneira de falar não causa prejuízo, mas serve como abreviação".

12. Teoria da Utilidade Marginal - Uma teoria econômica burguesa apologética que surgiu nos anos 70 do século XIX em antítese à teoria do valor-trabalho de Marx. De acordo com essa teoria, o valor de uma mercadoria é determinado por meio de sua utilidade marginal, ou seja, mediante avaliação subjetiva da utilidade daquela unidade mercantil, que satisfaz à necessidade menos premente do comprador, com dada grandeza do estoque de mercadorias. A teoria da utilidade marginal torna a grandeza do valor dependente da raridade relativa das mercadorias. $\mathrm{Na}$ realidade, contudo, a raridade relativa das mercadorias depende de seu valor mais ou menos elevado, que é determinado pelo gasto de trabalho socialmente necessário. O valor das mercadorias influencia, mediante os preços de mercado, a dimensão da demanda solvável, e a essa demanda se ajusta também a oferta de mercadorias. A teoria da utilidade marginal pertence aos fundamentos teóricos da moderna economia burguesa, porque ela aparece a seus representantes para camuflar a exploração dos trabalhadores no capitalismo (o Capital, Livro Terceiro, 1996, p.11). Consultar também Singer (1987, pp. 11-25).

13. Da mesma forma há um tempo médio socialmente definido para a produção de uma mercadoria, as taxas de juros auferidas pelos capitalistas seguem uma lógica análoga, ou seja, nos processos de trocas entre mercadorias, obtém-se uma taxa de lucro médio, muitas vezes similares 
em diferentes setores da economia capitalista, a exceção quando num dado momento ocorre um monopólio de um determinado setor, quando esse sozinho detém por um tempo processos únicos e tecnológicos de produção de uma determinada mercadoria.

14. Sobre a relação entre a renda fundiária e o processo da obsolescência espacial urbana, consultar Gonçalves, 2018.

15. Harvey (2013, p. 437)

16. Em:http://economia.estadao.com.br/noticias/economia,quando-dois-mais-dois-podem-naoser-quatro,39227,0.htm. Acesso em 22 de fevereiro de 2018.

17. Sobre a abordagem espacial dos preços hedônicos no mercado imobiliário consultar também Campos (2017).

18. HARVEY, David. Os limites do capital. São Paulo: Boitempo, 2013.

19. Ibidem, p. 436

20. Quando nos remetemos à ideia de comunicação entre os objetos para que ela ocorra estamos considerando três conceitos gerais relativos ao Espaço e aos objetos geográficos que o compõe, ou seja, a forma, a estrutura e a função que são indissociáveis entre si (SANTOS, 2004).

21. Ibidem.

22. O capitalismo tem como fundamento a constante transformação em seus parâmetros econômicos produtivos. As guerras e as revoluções tecnológicas possuem papel importante no processo de transformação da atividade industrial. Enquanto isso, o crescimento da população e o mercado de capitais impulsionam uma dinâmica ao sistema por meio "de novos bens de consumo, dos novos métodos de produção ou transporte, dos novos mercados e das novas formas de organização industrial criadas pela empresa capitalista" (SCHUMPETER, 1961 , p.110), ou seja, o fundamento principal se assenta na destruição criadora que se constitui em elemento chave para a compreensão do capitalismo, "que revoluciona incessantemente a estrutura econômica a partir de dentro, destruindo incessantemente o antigo e criando elementos novos

23. Sobre o ambiente construído e sua relação com a realidade urbana consultar também Harvey (2014).

24. Ibidem, p. 316

25. Ibidem, p.304

\section{RESUMOS}

A noção de obsolescência como tema de investigação se contrapõe ao que se convencionou denominar de deterioração urbana, que é imprecisa e não corresponde ao processo que levam a decadência física, funcional e econômica dos ambientes construídos. $\mathrm{O}$ conceito de obsolescência espacial urbana refuta a noção de deterioração por entender que a problemática imposta nos ambientes construídos da cidade é de ordem sócio geográfica. Observa-se que no processo de produção e reprodução do capital e do espaço geográfico, as áreas da cidade tidas como obstáculos ou que não se enquadram aos ideários e exigências da moderna economia global, estarão situadas no universo da obsolescência espacial. Distingue-se a realidade da obsolescência na esfera industrial com a que ocorre na dimensão urbana, demonstrando que o processo se dá nos interstícios das contradições do processo de produção e reprodução do espaço-mercadoria. Ao ter como foco de reflexão o mercado imobiliário analisa-se as relações existentes entre as categorias preço da terra e ambiente construído como forma de explicar e clarificar a gênese e os mecanismos que alimentam o processo da obsolescência espacial urbana. 
La notion d'obsolescence en tant que sujet de recherche s'oppose à ce qu'on appelle la détérioration urbaine, une expression imprecise et qui ne correspond pas aux processus responsables de la décadence physique, fonctionelle et économique des milieux construites. Par contre, le concept d'obsolescence spatiale urbaine montre que les problèmes associés à ceux milieux sont de l'ordre socio-géographique. En soulignant le marché immobilier, on analyse les rapports entre le prix de la terre et milieu construit afin d'expliquer la genèse et les mecanismes responsables de l'obsolescence spatiale urbaine.

The notion of Obsolescence as a subject of research opposes what is usually called Urban decay which is imprecise and doesn't suit the process that leads to physical functional and economic decay of a built-up area. The concept of urban spatial obsolescence denies the notion of urban decay by taking in that this whole issue that imposes itself on the built-up areas of the city is socio-geographic. It is observed in the production and reproduction of capital and the geographical space that the areas perceived as obstacles or which doesn't fit the global economy mindset and demands are set in the sphere of the Urban spatial obsolescence. Obsolescence in the province of industry contrasts with the one in the urban dimension demonstrating that the process takes place in the interstices of the merchandised-geographical- space production and reproduction contradictions. Focusing on the Real estate market, the existing relations among land price built-up environment are analysed as a mean to explain and clarify the genesis and mechanisms which Urban spatial obsolescence feeds off.

La noción de obsolescencia como tema de investigación se opone a lo que convencionalmente se ha denominado deterioro urbano, que es impreciso y no responde al proceso que conduce al deterioro físico, funcional y económico de los ambientes construídos. El concepto de obsolescencia espacial urbana refuta la noción de deterioro al entender que la problemática impuesta a los ambientes construídos de la ciudad es de orden socio-geográfico. Se observa que en el processo de producción y reproducción del capital y del espacio geográfico, las áreas de la ciudad tenidas como obstáculos o que no se ajustan a los ideales y requerimientos de la economía global moderna, se ubicarán en el universo de la obsolescencia espacial. La realidad de la obsolescencia en el ámbito industrial se distingue de la que ocurre en la dimensión urbana, demostrando que el proceso tiene lugar en los intersticios de las contradicciones en el proceso de producción y reproducción del espacio-mercancía. Centrándonos en la reflexión sobre el mercado inmobiliario, se analiza la relación entre las categorías precio del suelo y ambiente construido como una forma de explicar y esclarecer la génesis y los mecanismos que alimentan el proceso de obsolescencia espacial urbana.

\section{ÍNDICE}

Mots-clés: obsolescence spatiale urbaine, détérioration urbaine, ville, prix de la terre, milieu construit.

Palavras-chave: obsolescência espacial urbana, deterioração urbana, cidade, preço da terra, ambiente construído.

Palabras claves: obsolescencia espacial urbana, deterioro urbano, ciudad, precio del suelo, ambiente construido.

Keywords: urban spatial obsolescence, urban decay, city, land price, built environment. 


\section{AUTOR}

\section{ANDRÉ VINÍCIUS MARTINEZ GONÇALVES}

Doutor em Geografia pela Universidade Estadual de Campinas (UNICAMP) e Mestre em Geografia pela Universidade de São Paulo (USP). Atualmente é professor da Universidade Federal do Paraná - SEPT. Integrante do grupo de pesquisa Problemática Urbana e Ambiental da UNICAMP.

Email:reclusgeo@hotmail.com 